\title{
Curriculum Design, Implementation and Parental Involvement in the Education of the Deafblind: South African Teachers' Perspectives
}

\author{
Mbulaheni Obert Maguvhe (PhD) \\ Department of Inclusive Education, College of Education, University of South Africa \\ Pretoria, Republic of South Africa, P.O. Box 392 , UNISA \\ Pretoria, Republic of South Africa, 0003 \\ Email:maguvmo@unisa.ac.za
}

Doi:10.5901/mjss.2014.v5n20p1486

\begin{abstract}
This study investigated the perceptions of teachers of deafblind learners on curriculum design, implementation and parental involvement. Three telephonic and two face-to-face interviews were conducted with five female teachers of the deafblind at five special schools in five of the nine provinces of South Africa. It was found out that curricula for the deafblind were not streamlined to the national curriculum and schools designed and awarded their own certificates to enable progression and employment. In addition, unit standards for teaching deafblind learners did not exist in the Umalusi repository. Curricula for the deafblind could be improved if acceptable unit standards with relevant specific outcomes were generated. Training of district team members and teachers on the teaching of the deafblind should be ongoing. Finally, parents of deafblind learners should play an active role in the education of their children, in partnership with teachers. The findings of this study demonstrate that teachers have knowledge and experience that could be used to design curricula for deafblind learners and as well create synergies with both the Department of Basic Education and the parent community. Teachers of the deafblind know their training needs, and expect the Department of Basic Education to develop their skills.
\end{abstract}

Keywords. Deafblind. Services. Educational programmes. Unique needs. Educational team. Residual vision and hearing.

\section{Introduction}

Deafblindness is a low incidence condition which is rarely discussed in public circles. Minor coverage in public talk goes with low societal preparedness to accommodate people who are deafblind. Literally, society has forgotten that it is made up of members who include the deafblind. This article's aim was to gather the perceptions of teachers at schools with deafblind units on different curriculum matters and deafblindness. Their answers could remind the literate public about the educational needs of the deafblind. The article covered the perceptions held by teachers of deafblind learners on matters of curriculum design, implementation and parental involvement.

It is important to clarify the nature of deafblindness in order to arrive at a good definition of the condition. A person who is deafblind is surely not just unable, with the best corrective lenses to see at a distance of twenty feet, or, peripheral vision limited to twenty degrees or less. Again, he or she is not just a person who is unable to hear and understand speech. The former is a blind person, the latter is a deaf person. To be deafblind, you must have a dual sensory impairment in both hearing and vision. Therefore, for the purpose of this article, the following descriptive definition will be adopted: ".... deaf-blindness is a dual disability, with the effects of one loss compounding those of the other, it is usefully described as losses of vision and hearing that together make methods of communication, and therefore programs of all kinds, that are suitable for the deaf or blind person inadequate for the affected person." (Yoken 1979, 7). Deafblind South Africa (Deafblind SA) adds that: 'Deafblindness ... significantly affects communication, socialisation, orientation and mobility, access to information and daily living' and figuratively summarises the condition as 'isolation and chaos' (Deafblind SA 2009, web). Clark (1996) further classifies the deafblind as congenitally and adventitiously deafblind.

If Deafblind SA is indeed correct to summarise deafblindness as 'isolation and chaos' it stands to reason that the deafblind need special assistance in order to receive communication in a majority of everyday situations. Many people live, interact and attend schools, etc. with the deafblind but do not understand them. The temptation to feel that one is better than the deafblind and ignore them looks big when one does not know how to communicate with them. The final result of this 'isolation' is that "deafblind people are amongst the most marginal, the poorest of the poor communities in the world. Their experience of "social exclusion" - to use the jargon of the international community - is as profound and as debilitating, as any of the poorest communities in our society." (Sense International 2012, web). According to Sense 
International, the deafblind are uniquely prone to abuse: they are commonly confined to institutions, stigmatized, isolated in both society and family, and they are not given the chance to work or assume befitting roles in society. The author ascribes these dire inequalities to the fact that they are a minority within a minority (implying that they are a small percentage of persons with disabilities). Consequently, their rights and interests are downtrodden. Their unique needs are not considered and advocated for.

Human Rights Education Associates $(2011,1)$ actually lament that discrimination is still common in the United States and around the world. They proceed to say that this is despite the fact that "the Universal Declaration of Human Rights recognises the inherent dignity and the equal and inalienable rights of all members of the human family, and the U.S." This state of affairs impels one to investigate the perceptions of teachers of the deafblind on the education of those children.

Throughout history, fundamental rights have been denied to certain groups of people due to political motivations, ruthlessness, ignorance, indifference, racial intolerance etc. It has always been difficult for the deafblind to go across the bridge of acceptance and understanding in the past and it is still the case today. We forget or ignore the fact that, "every human being, from the richest to the poorest, from the youngest to the oldest, from the most physically fit to the most misshapen, has the inalienable right to existence and to as normal a life as possible under existing circumstances." (Konar 1988, 3).

Society at large still has many misconceptions about (and negative attitudes towards) deafblind people. The following are a few good examples:

\section{Table I: Misconception Reality}

\begin{tabular}{|l|l|}
\hline All deafblind people can be as successful as Helen Keller. & The IQ of deafblind people is as varied as that of all people. \\
\hline All deafblind people are totally deaf and totally blind. & $\begin{array}{l}\text { Some are but many have some residual hearing and/or residual } \\
\text { vision. }\end{array}$ \\
\hline All deafblind people are retarded and cannot learn. & Some are but most aren't. \\
\hline $\begin{array}{l}\text { All deafblind people are helpless and totally dependent on } \\
\text { others. }\end{array}$ & Some lead active, independent lives. \\
\hline Deafblindness is contagious. & $\begin{array}{l}\text { There are many different causes of deafblindness ranging from } \\
\text { accidents to birth defects. }\end{array}$ \\
\hline $\begin{array}{l}\text { Deafblind persons can not benefit from training, cannot work in } \\
\text { competitive employment, and can only work in sheltered } \\
\text { workshops. }\end{array}$ & $\begin{array}{l}\text { There are many deafblind people in different vocations, both } \\
\text { professional and non-professional. }\end{array}$ \\
\hline $\begin{array}{l}\text { Deafblind persons require no specialized services beyond those } \\
\text { of the general rehabilitation population. }\end{array}$ & $\begin{array}{l}\text { Interpretive services are unique for this population as well as some } \\
\text { adaptive equipment. }\end{array}$ \\
\hline $\begin{array}{l}\text { Deafblind persons have special needs that always require } \\
\text { separate, segregated services. }\end{array}$ & $\begin{array}{l}\text { While they may require special interpreters, there is no need for } \\
\text { them to be separate from others receiving educational or } \\
\text { rehabilitation services. }\end{array}$ \\
\hline
\end{tabular}

These misconceptions and attitudes influence the decisions and plans to be made concerning the education of the deafblind, often leading to their rejection or inappropriate delivery of comprehensive services. Some author lament the revulsion with which both authorities and other public persona react to persons who are deafblind; and hurry to show that something could be done to reduce such reactions. Sauerburger (1993) discusses matters on understanding public reactions to deafblind people as a way of preventing 'some unfortunate situations which occur when ill-prepared professionals and clients are thrown in at the deep end' (Guest 1993, 113). Similar observations are made by Konar $(1988,24)$, who said, "Existing public attitudes of indifference, avoidance and fear can be reshaped into more affirmative channels, neglect can be replaced by concern, hopelessness by constructive and purposeful activity."

Clark $(1994,3)$ explains that the deafblind are a very small population yet their needs are very high 'and [they] often require an intensive level of support over a prolonged period of time'. On the backdrop of that information, Clark $(1994,3)$ discusses the slow genesis of legal statutes on the care of persons who are deafblind in the United Kingdom in the 1990s. Clark (1994) cherishes the enactment of the National Health Scheme (NHS) and Community Care Act of 1990, but loathes its interpretation made by Local Authorities; that resources for Community Care should be allocated based on the size of the overall budget instead of considering the needs of recipients as the main determining factor for provision. Clark is of the opinion that budgets should be based on the needs of Community Care Agencies rather than determined by the amount of money available in a local authority budget. Budget based allocation could be interpreted as institutionalized neglect for a sector, which serves the needs of marginalized people, who include the deafblind. 
Developments on the education of the Deafblind have evolved at different paces. Engagements with the deafblind have not been uniform over time. It is possible to find anecdotal evidence of the existence and treatment of deafblind people at almost any time in recorded history. For instance, it is reported in Governor Winthrop's Journal of the Massachusetts Bay Colony in 1637, that in Ipswich, there was an old woman who came from England being deafblind, yet the son could make the mother understand anything and know any man's name by the sense of feeling. The son would write upon the woman's hand letters of the name and by other such means, would, inform the woman. And again, it is reported that a young man, James Mitchell, who was born in Scotland in 1795, is considered to have made remarkable success despite being handicapped. James Mitchell took full advantage of all the senses of touch, taste and smell. Despite the young man's abilities, no effort was made to offer him educational opportunities. Forty two years after the James Mitchell saga in Scotland, Dr. Samuel Gridley Howe initiated the formal education of deafblind children in the United States of America. It was Dr. Howe whose brave efforts opened the eyes of the world to the possibility of interacting with and educating the deafblind. Dr. Howe's careful documentation of Laura Bridgman's education at Perkins School for the Blind in Massachusetts from 1837 to 1857 provided the framework which formed the basis for work with deafblind persons by all teachers who followed. Before him, there were people who worked diligently and tirelessly to improve the welfare of the deafblind in their own right.

In 1888, Helen Keller was the second deafblind student to be admitted to Perkins School for the Blind. Anne Sullivan became her teacher and companion for many years. In 1896, Helen attended Cambridge School for Girls. In 1904, Helen Keller became the first deafblind person to graduate from college. The degree was obtained from Radcliffe. Helen Keller led an active life for her own satisfaction and for the benefit of other handicapped persons throughout the world. Robert Smithdas was the second deafblind person to obtain a degree from an institution of higher learning. Robert Smithdas received the Bachelor of Arts degree Cum Laude from St. John's University in Brooklyn, New York. In 1953, Robert Smithdas became the first deafblind person to receive a Masters degree. It was awarded from New York University where Robert Smithdas majored in vocational guidance and rehabilitation of the handicapped. Like Helen Keller, Robert Smithdas achieved these successes through the help of a dedicated companion. In the Soviet Union, from 1925 - 1948, Olga Skorokhodova was equally well known as a student with high academic abilities. Also famous was her teacher Professor Ivan Sokolyansky (Meshcheryakov, 1974). Meaningful achievement was recorded in the education of the deafblind where there was dedication by the teacher or other close companion. That dedication seems to be a rare fit in today's classrooms.

\section{Research Questions}

The study solicited answers to the questions listed below:

1. In your opinion is it true that curricula for the Deafblind do not lead to well recognized certificates?

2. How could curricula for the deafblind be improved in South Africa?

3. What is the importance of collaboration between parents of deafblind learners, teachers, other professionals in the education of the deafblind?

\section{Method}

\subsection{Design}

The survey design was used for the study. It was appropriate because surveys are good where non-experimental opinions are being sought from relevant publics (Welman, Kruger \& Mitchell 2005). The surveys were conducted in the form of telephonic interviews (three teachers from three of the five schools with units for the deafblind learners) and faceto-face interviews (two teachers from two of the five schools with units for deafblind learners). The interviews employed the same questions and responses were tape recorded.

\subsection{Sample}

The sample comprised five teachers of the deafblind from five schools that teach the deafblind. The sample was distributed as shown in Table II below: 
Table II: Sample Characteristics

\begin{tabular}{|l|l|c|c|}
\hline Province & School & Number of Teachers & Gender \\
\hline Limpopo & Siloe School for the Blind & 1 & $\mathrm{~F}$ \\
\hline Gauteng & Sibonile School for the Blind & 1 & $\mathrm{~F}$ \\
\hline Free State & Bartimea School for the Blind and Deaf & 1 & $\mathrm{~F}$ \\
\hline KwaZulu-Natal & Arthur Blaxall School for the Blind & 1 & $\mathrm{~F}$ \\
\hline Western Cape & Pioneer School for the Blind & 1 & $\mathrm{~F}$ \\
\hline Total & & 5 & Females \\
\hline
\end{tabular}

\subsection{Instruments}

The research used semi-structured interview schedules for telephonic interviews and semi-structured interview guides for face-to-face interviews. Telephonic interviews were used because they are well suited to simple questions, and they are relatively less costly than face-to-face interviews (Welman, Kruger \& Mitchell 2005). These were used with participants from more distant provinces. Face-to-face interviews were used with participants from Gauteng and Limpopo, which are near to the researcher's place of work. Face to face interviews offer the advantage of flexibility and adaptability (Welman, Kruger \& Mitchell 2005).

\subsection{Data Collection}

Data was collected in May 2012. The two face-to-face interviews were conducted during the first and second weeks of May while the author was on his routine educational support visits to schools for the blind. Each one lasted for about forty minutes. The remaining three telephonic interviews were conducted in one day, in the third week of May 2012. Each interview lasted an average of twenty minutes. Both face-to-face interviews and telephonic interviews were personally administered by the researcher, who sampled the participants purposefully as only those who taught the deafblind were to be interviewed. Responses were transcribed in script and braille during proceedings, and also recorded on tape.

\subsection{Data Analysis}

Data was analysed qualitatively by reviewing the responses as captured in braille and script, comparing with actual narratives recorded on tape. Results were used to draw conclusions by the researcher on the meaning of each response.

\subsection{Ethical Considerations}

Respondents were informed in advance on the purpose of the study. The researcher ensured that respondents gave consent to the research process by signing consent forms before interviews commenced. Responses to questions were accordingly coded. The researcher assured participants that upon publication, the article would be made available to them.

\section{Results}

Responses made by different teachers on the three questions showed that a notable gap exists in their perceptions about the capacity of the South African education system to cater fully for the needs of deafblind learners; however they experienced similar problems in their daily work with deafblind children.

\subsection{Results by question}

1. In your opinion is it true that curricula for the deafblind do not lead to well recognized certificates?

All responses to the question revealed that curricula for the deafblind were not streamlined to the national curriculum, resulting in schools awarding institution-based certification. School-based certificates were not nationally recognized and they were strange to potential employers.

Responses to this question also showed that unit standards applied to the teaching of deafblind learners does not exist in UMALUSI repository. 


\section{How could curricula for the deafblind be improved in South Africa?}

Responses to the second question on the improvement of the curriculum showed that the curriculum could be improved provided that:

i. acceptable unit standards with relevant specific outcomes are generated;

ii. professionals who support teachers are well trained and knowledgeable;

iii. teachers undergo regular in-service training, and

iv. enough resources are supplied for teaching and learning.

Respondents also revealed that teachers benefited tremendously from a strong training foundation therefore it was important for the country to establish an institution that would carryout that mandate, even in collaboration with similar international organs.

3. What is the importance of collaboration between parents of deafblind learners, teachers, and other professionals in the education of the deafblind?

Responses to this question were two-fold. In practice teachers of deafblind learners did not work with parents on a daily basis. For some parents, partnership only applied to sending children to school (and sometimes never fetching the children back home). There was no meaningful co-operation between teachers of deafblind learners and parents that would give educational leverage to the class on a daily basis.

Respondents revealed that parent-teacher partnerships were a boost to the teacher's understanding of the learner but quickly noted that in most cases they were not working in close liaison with parents of deafblind learners. They further revealed that including parents of deafblind children in the school governing body (SGB) could increase their participation.

\section{Discussion}

\subsection{Discussion of Results by Question:}

Question 1 In your opinion is it true that curricula for the deafblind do not lead to well recognized certificates?

Responses to the question revealed that curricula for the deafblind were still predominantly for institution-based certification. They did not lead to widely recognized (national) certificates. This shows that the curricula they were applying in classes for the deafblind were different from those offered in other schools. They do not offer mathematics, life sciences, physical sciences, economic management sciences etc., which have a bearing on participation in economics, politics and science. In apparent frustration one respondent said, 'Certainly it is only a few deafblind students who make it to nationally recognized qualifications. A vast majority just get educational qualifications crafted by the institutions where they go to school.' What seems to be compounding the problem, according to another respondent was the fact that no one seems to "know that the deafblind are among other learners in this school, as a result there is no meaningful provision furnished for my class even from district offices. Working with deafblind learners requires intensive one on one support but that means the teacher should have one or two classroom assistants." The last respondent on this question was of the idea that, "There is no capacity in the country at present for meeting the needs of the deafblind widely. Only well-to-do schools are able to offer a few deafblind learners the same curriculum as that offered to learners who are not deafblind. That is a problem.' Lamenting similar circumstances, Yoken $(1979,3)$ asserted 'we have barely scratched the surface' in servicing deafblind individuals.

It was further revealed that district support specialists were not conversant with curriculum matters for deafblind learners. In backing this view one respondent echoed the following sentiment: 'When district education subject advisors eventually come to our school, they offer advice on school administration, not various ways in which I could impart skills to my deafblind learners.' The author of this article believes that with proper communication methods, a conducive learning/teaching environment and an accessible curriculum; deafblind learners can also benefit and thrive educationally.

Question 2 How curricula for the deafblind could be improved in South Africa?

Pertaining to the second question on how curricula for the deafblind could be improved, respondents maintained that relevant unit standards should be generated, district support personnel be well trained, teachers be adequately inserviced and enough resources be provided for successful teaching and learning to take place. It emerged from the study that there were mixed feelings on this question. Mixed feelings could be attributed to exposure to international best practices or lack thereof.

While the above conditions for the improvement of the curriculum were proposed by four of the five respondents, the fifth respondent maintained that: 'There is now great need to send profoundly knowledgeable and practical district support staff to special schools for them to offer useful advice and improve our schools. Improvements in teaching are 
yielded through evidence-based practice, and that requires appropriately qualified subject advisors. I do not see them coming to my aid though; they are embedded in administrative chores.' The latter feeling of despondence on the part of this respondent excavates important underpinnings on practical issues in programme implementation. The author of this article observes that district support personnel need skills in special education in the face of their new roles. As Gee $(1994,13)$ puts it, they should develop themselves on core aspects of education for the deafblind; including educational planning and instruction, 'determining the means by which the student will receive information, and how instructional techniques will be adapted to the learner.' Without rigorous conscientisation and training on deafblindness, they will not be able to cascade knowledge downwards.

Probably because some of the trainers at the Department of Basic Education need training in special education themselves, teachers have few chances of getting trained on topics that matter to them. One respondent highlighted that: 'Important skills such as the compilation of a good schedule should be cascaded to every teacher through workshops and other training avenues but so far I got such training once, through Perkins School for the Blind's Summer Institute in Durban in 2009. We need more such training to gain confidence and do more for our learners.' Boshielo (1989) sums up that sentiment with a plea for people to learn from each other.

When district learner support teams are appropriately trained, they will be able to impart information in areas such as designing functional and academic school-based curricula for the deafblind. They will also be able to do several other things suggested by one respondent who received training in the United States of America. That respondent articulated it thus: 'I am one of the few lucky teachers to have studied at Perkins School for the Blind in Boston, USA. I know that a teacher should be trained to design functional and academic school-based curricula for children who are deafblind. Yes, it takes rigour to analyse level descriptors for accreditation by Umalusi, but when that is thoroughly done, school-based curricula could be integrated into the national curriculum. They would embody the required applied competences at different levels attainable by individual learners: foundational, practical and reflexive competences. Even 'autonomy of learning' as an ability to engage in life-long learning would also be deemed to be built into the individual learner as he proceeds through the education system. I am personally skeptical about the National Department of Education's affinity to the idea of integrating the curriculum for deafblind learners into the national curriculum; although such a move would enable these learners to get competence-related certificates on completion of their education.' The sentiment echoed above strengthened the notion that school-based curricula should be merged into the national curriculum to enable deafblind learners to pursue further education and to later, engage in gainful employment.

Question 3 What is the importance of collaboration between parents of deafblind learners, teachers and other professionals in the education of the deafblind?

Responses to this question were two-fold. In practice teachers of deafblind learners did not work with parents on a daily basis. The concept of partnership in this regard only applied to parents sending children to school. There was no meaningful co-operation between teachers and parents of deafblind learners. The author of this article believes that lack of co-operation could be a result of long distances between home and school, and the belief that schools were actually homes where deafblind children enjoyed their times with friends who were like them. This observation is confirmed by one respondent who noted that some parents never fetched their children home on school holidays for years.

Teachers are aware of the importance of involving family members, particularly parents. However, they are concerned that it is not always possible to be with parents. One respondent articulated that awareness thus: "Very few children are deafblind, so it is very rare to find many parents resident anywhere near their children's schools. Sometimes you just find no parents to involve in the activities of your class, but when parents participate, they get to learn how to communicate with their child more effectively. The teacher also gets to know the learner better as the two exchange notes and experiences.'

Another respondent was of the idea that even in instances whereby parents met with teachers; they sometimes expected the teacher to tell them everything. The respondent stated: 'Many parents have the mentality that it is the teacher who knows everything, although parents constitute the majority of the school governing body.'

Respondents were of the view that to achieve the maximum benefits derived from parental involvement; parent committees should be appointed which include parents of deafblind children so that their voices would encourage other parents of deafblind learners. In addition, better representation of those parents could help in designing a system for early identification and appropriate educational intervention.

\section{Conclusion}

Findings from this study lead to the following conclusions: curricula for the deafblind were not streamlined to the national curriculum, schools award their own certificates to deafblind learners and unit standards for teaching deafblind learners 
were non-existent in the Umalusi repository. Furthermore, improvement of the curriculum for deafblind learners depends on the generation of acceptable unit standards with relevant specific outcomes, the establishment of an effective training programme for both district support personnel and teachers - and the accumulation of enough requisite resources. Finally, desired collaboration could not take place because of distances between home and school but teachers were well aware of the benefits of partnership between home and school.

\section{Recommendations}

It is recommended that curricula for the deafblind be streamlined to the national curriculum.

Umalusi recognized unit standards with clear and achievable outcomes for teaching deafblind learners be generated.

It is recommended that an active training programme be developed and designed for both district support specialists and teachers. The programme should be endorsed by the South African Qualifications Authority.

Despite poor linkages between home and school, it is recommended that schools make a concerted effort to woe parents into a constructive partnership.

\section{Terms}

Umalusi: The Department of Basic Education's examinations and qualifications repository.

\section{References}

Boshielo Sam. We Need To Learn From Each Other, Imfama, 29th Edition, South African National Council For The Blind, Pretoria, South Africa, (1989).

Clark, Rodney. Community Care for Deafblind People. What is it? Where is it? The British Journal of Visual Impairment. 12, no. 1 (1994): 3-6.

Clark Rodney. Helping Those with Multisensory Impairments: The long slow haul to better training and services. The British Journal of Visual Impairment. 14, no. 3 (1996): 118-119.

Deafblind SA 2009. Chaos and Isolation. Downloaded on 14 March 2012, from http://www.deafblindsa.co.za/index/php?option= com_content\&view=article\&id=6\&ltemid $=10$.

Gee, Kathleen. Inclusive Instructional Design: Facilitating Informed and Active Learning for Individuals Who are Deaf-blind in Inclusive Schools. San Francisco: California Research Institute, 1994.

Human Rights Education Associates 2011. Service Learning: Lesson Plans and Projects. (http://www.hrea.org/index.php?doc_id=447) (accessed March 9, 2012).

Konar, Valerie. Strategy for Serving Deaf-blind Clients, Arkansas Research and Training Center in Vocational Rehabilitation, 1988.

Meshcheryakov, Alexander. Soviet Psychology: Awakening to Life - Deaf-blind Children. 1974. http://www.marxists.org/archive Imeshcheryakov.awakening/introduction.htm

(accessed March 9, 2012).

Sauerburger,Dona. Independence without sight and sound: suggestions for practitioners working. 1993. http://www.sage publications.com

Sense International. 'Indian "story"' (http://www.sordoceguera.org/information/historias-reales/175-a-indian-story.html) (accessed March 18, 2012).

Welman, Chris., Kruger, Fanie and Mitchell, Bruce. Research Methodology (3rd Edition). Cape Town: Oxford University Press Southern Africa (Pty) Ltd, 2005.

Yoken, Carol. Living with Deaf-blindness: Nine Profiles. Washington, DC: Gallaudet College, 1979. 